\title{
Experimental Study on Effects of Concrete Properties by Partially Replacement of Industrial Waste: A Green Concrete
}

\author{
Amreen Khatun ${ }^{1, a}$, Tanuja Rani ${ }^{2, b}$ \\ a Assistant Professor at APG Shimla University, India \\ ${ }^{\mathrm{b}}$ Assistant Professor at APG Shimla University, India
}

\begin{abstract}
A B S T R A C T
Green concrete is concrete produced using waste materials obtained from various sources to develop an eco-friendly construction and reduce carbon emissions. The present experimental study is carried out to produce concrete using waste material from different industries to partially replace traditional concrete. Many research studies have been made using different waste materials which are available and useful as a replacement. The present study deals with industrial waste such as foundry sand (FS) and ground granulated blast furnace slag (GGBS) in the concrete so that the emission can be reduced and contribute to the environment. This study prepared two mixes for M35 Grade by replacing industrial wastes partially in the concrete mix. The first mix was prepared by partially replacing foundry sand with fine aggregates in proportions of $15 \%, 20 \%, 25 \%$ and $30 \%$. The second mix was prepared by partially replacing the ground granulated blast furnace slag with cement in proportions of $30 \%, 40 \%$ and $50 \%$. Test results were conducted to check the workability and compressive strength of the mixes prepared. These were then compared with the properties of conventional concrete at the end of 7 and 28 days. Test results indicate that $25 \%$ of FS and $30 \%$ of GGBS are the optimum percentages of industrial waste to use compared to conventional concrete properties at the end of 7 and 28 days. The present study also indicates the economic benefits of partially replacing the waste materials by reducing carbon emissions, and the study is beneficial to produce eco-friendly green concrete.
\end{abstract}

\author{
A R T I C L E I N F O \\ Keywords: \\ Fresh Properties, Compressive \\ strength, Ground Granulated Blast \\ Furnace Slag (GGBS), Waste \\ Foundry Sand (FS). \\ *Corresponding author: \\ amreenkhatun02@gmail.com \\ itsmetanujaminhas@gmail.com \\ (Amreen Khatun Tanuja Rani) \\ Article history: \\ Received: 14072021 \\ Revised: 27122021 \\ Accepted: 28122021 \\ DOI : \\ https://doi.org/10.51410/jcgirm.8.2.6
}

\section{INTRODUCTION}

\subsection{General}

Concrete is an integral part of the construction industry, and the mixture is composed of materials like cement, fine aggregates, coarse aggregates and water. Concrete is an important material in construction as it fulfils the requirements of workability, durability, strength and ability to resist fire. Concrete is also prepared by adding some admixtures into the mix to enhance the properties of concrete. In the present day, the increasing demand for industrialization is also increasing the production of industrial waste, and its secure disposal is a matter of concern. This study also focuses on the economic benefits of using waste materials obtained from industries and agriculture activities. Production of eco-friendly concrete is a prime duty of every researcher leading to industrial benefits obtained from any construction works. Therefore, many researchers have placed minimizing waste 
obtained from industries and agricultural fields on their priority list, together with the utilization of waste material as a partial replacement with the concrete mix components. This study indicates that the utilization of industrial and agricultural waste as a substitute in concrete mix leads to waste minimization and contributes to environmental protection by reducing carbon emissions produced in concrete production.

In this research, an experimental study was carried out to check the optimum percentage of utilizing industrial waste and investigate the concrete mix's workability and compressive strength. In the present study, the first mix was prepared by partially replacing foundry sand with fine aggregates in different proportions of $15 \%, 20 \%, 25 \%$ and $30 \%$ and test results were conducted to check the workability and compressive strength of the prepared concrete. The result indicates that the optimum percentage for concrete utilization is $25 \%$ of foundry sand replacement with fine aggregates. In the second concrete mix, the optimum percentage of foundry sand, i.e. 25\%, along with partial replacement of GGBS with cement in different proportions of 30\%, $40 \%$ and $50 \%$, is prepared. Test results were conducted to check the workability and compressive strength of the mix at the end of 7 and 28 days. Results obtained from the second mix indicate that $25 \%$ of foundry sand and $30 \%$ of ground granulated blast furnace slag are the optimum percentages for utilizing industrial waste. This composition also indicates higher workability and compressive strength compared to conventional concrete properties at the end of 7 and 28 days ( Sheikibrahim et al., 2018)

The investigation carried out for this study also indicates that using these industrial wastes as substituents for preparing concrete mix helps develop an eco-friendly and green construction material and leads to cost-effective construction for the industry.

\section{METHODOLOGY}

This experimental study was carried out to investigate the performance of concrete mixtures prepared using different industrial wastes without compromising the performance and characteristic performance of the concrete, including workability, durability, and strength of the concrete. Concrete is prepared for M35 Grade mix, and a total of 72 cube specimens were cast to check the fresh and mechanical properties of the concrete after curing for 7 and 28 days-the nominal mix proportion of M35 grade mix as per recommendations given in IS Code 456. Concrete cubes were cast for Mix 1 concrete and Mix 2 concrete and conventional concrete using 150*150*150 mm size moulds (Kumbhar and Sangar, 2011)

\subsection{Material Used}

\subsubsection{Cement}

Cement plays a binding role in concrete mixtures, which holds all the concrete mix materials together. The cement used for this study to prepare concrete mixture is Portland Pozzolana Cement sieved 
through a $90 \mu$ sieve. The various tests were performed on cement to investigate the properties of the cement as per regulations given by IS Code: 1489 (Part-1). The initial setting time recorded for PPC was 90 minutes, and the final setting time recorded was 8 hours when performing lab tests (IS: 102622009, 2009).

\subsubsection{Fine Aggregates}

Fine aggregates are particles that pass through $4.75 \mu$ and are retained on a $75 \mu$ sieve as per standard recommendations given by IS: 456. In this study, the fine aggregates used are obtained from river sand made up of crushed aggregates. Initial testing is done in laboratories to investigate the properties of fine aggregates to check the suitability of the material for preparing the concrete mix.

\subsubsection{Coarse Aggregates}

Coarse aggregates are defined as aggregates retained on a $4.75 \mathrm{~mm}$ sieve, and tests were performed to investigate the initial conditions as per recommendations given by IS Code 383: 1970. This study uses coarse aggregates ranging from $10 \mathrm{~mm}$ to $20 \mathrm{~mm}$ to prepare the concrete mix. The coarse aggregates were properly washed to remove the unwanted dust and impurities attached to the aggregates and dried properly using dry surface conditions.

\subsubsection{Foundry Sand}

Foundry Sand is a waste material obtained from casting industries obtained from the casting of ferrous and non-ferrous metals. Foundry Sand is used as a partial replacement with fine aggregates to investigate the optimum utilization percentage in the concrete mix. The utilization of FS is not only helpful to reduce the carbon emissions in the production of concrete but also helpful for minimizing waste and preparation of greener concrete. In the present study, FS is used from Bhoparai Metals Pvt. Punjab-Mohali-India (Bhimani, et al. 2013).

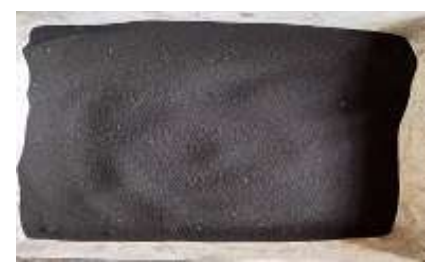

Figure1 Foundry Sand

Source: Author's Own Photo

\subsubsection{Ground Granulated Blast Furnace Slag}

Ground Granulated Blast Furnace Slag is used as waste material as a partial replacement with cement to find the optimum percentage for utilizing industrial waste. For the present study, the GGBS used is obtained from ECOGEN industry private Limited Dehradun HP. The utilization of 
GGBS in the concrete mix is helpful to reduce the heat of hydration effect. In addition, the study indicates that usage of GGBS in optimum percentages is responsible for increased strength and is beneficial for enhancing other properties of concrete, like workability and durability (Karri et.al, 2015).

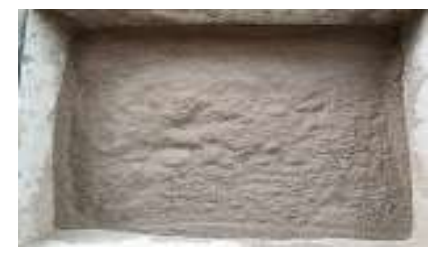

Figure 2 Ground Granulated Blast Furnace Slag

Source: Author's Own Photo

\subsubsection{Super Plasticizer}

In the present study, a superplasticizer is used to prepare the concrete mix so that the properties of the concrete mix can be enhanced. RHEOPLAST-SP-450 superplasticizer is used in this experimental investigation, a water-retardant admixture, and the dosage used for mixing is $20 \%$ $30 \%$. The superplasticizer used for the study is responsible for improving the workability of fresh concrete and gaining the concrete's ultimate strength.

\subsubsection{Water}

In this experimental investigation, locally available tab water is used to prepare the mix of concrete, and for curing purposes, casted cubes are used. The laboratory testing is done to check the quality standards of water used for preparing the mix. The water used for mixing was clean, free from impurities like salts, oil and acid.

\section{TEST PROCEDURE}

\subsection{Mix Proportion}

M35 grade concrete is considered, and the mix was prepared as per regulations given by IS Code 10262-2009 and IS: 456. Two concrete mixes were prepared by utilizing industrial waste. Mix 1 is prepared by partially replacing foundry sand with a volume of fine aggregates in different proportions of $15 \%, 20 \%, 25 \%$ and $30 \%$. Test results were conducted to investigate the workability and compressive strength of the concrete. Mix 2 is prepared by partially replacing the GGBS with a volume of cement in different proportions of $30 \%, 40 \%$ and $50 \%$. Test results were conducted to check the optimum percentage of utilizing FS and GGBS in the concrete mix, and results obtained for workability and compressive strength were compared with the properties of conventional concrete. 
Table 1 Values for Mix proportion of M35 Concrete Grade

\begin{tabular}{|c|c|c|c|c|}
\hline Batch Units & Water & Cement & $\begin{array}{c}\text { Fine } \\
\text { Aggregates } \\
\text { (Kg) }\end{array}$ & $\begin{array}{c}\text { Coarse } \\
\text { Aggregates } \\
\text { (Kg) }\end{array}$ \\
\hline Volume in Cubic meter & 190 & 420 & 685 & 1170 \\
\hline Ratio of materials & 0.45 & 1 & 1.63 & 2.8 \\
\hline
\end{tabular}

Source: Author's Compilation

Table 2 Values ofMix proportion forFS and GGBS

\begin{tabular}{|c|c|c|c|c|c|c|}
\hline S No. & GGBS & FS & Cement & $\begin{array}{c}\text { Fine } \\
\text { Aggregates }\end{array}$ & $\begin{array}{c}\text { Coarse } \\
\text { Aggregates }\end{array}$ & Water \\
\hline $\mathbf{1 .}$ & $30 \%$ & $25 \%$ & 336 & 513 & 1170 & 151 \\
\hline $\mathbf{2}$. & $40 \%$ & $25 \%$ & 294 & 513 & 1170 & 132 \\
\hline $\mathbf{3 .}$ & $50 \%$ & $25 \%$ & 252 & 513 & 1170 & 113 \\
\hline
\end{tabular}

Source: Author's Compilation

\section{TEST RESULTS}

\subsection{Test results for workability}

This study test is conducted to check the workability for concrete Mix 1, concrete Mix 2 and conventional concrete. Test results shown in Table 3 indicate that the test values obtained for concrete Mix 2 in which 25\% replacement of FS with fine aggregates and 30\% replacement of GGBS with cement shows higher workability of $110 \mathrm{~mm}$ when compared to other trials mixes and slump for conventional concrete.

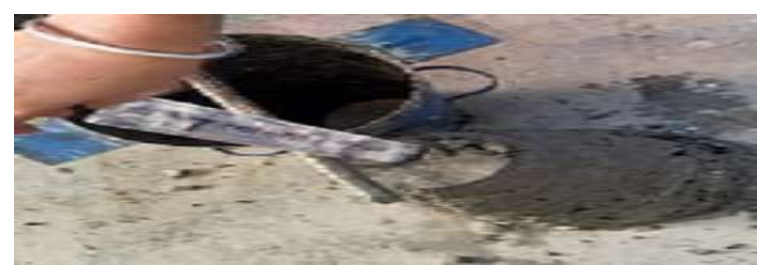

Figure 3 Figure for slump test 
Source: Author's Own Photo

Table 3 Values of Slump for concrete mix with FS and GGBS

\begin{tabular}{|c|c|c|}
\hline Sr. No. & Mixture & $\begin{array}{c}\text { Slump Value } \\
\text { (mm) }\end{array}$ \\
\hline 1. & $\begin{array}{c}\text { Conventional } \\
\text { Concrete }\end{array}$ & 105 \\
\hline 2. & FS 25\% + GGBS 30\% & 110 \\
\hline 3. & FS 25\% + GGBS 40\% & 65 \\
\hline 4. & FS 25\% + GGBS 50\% & 25 \\
\hline
\end{tabular}

Source: Author's Compilation

\subsection{Test Results for Compressive strength}

Tests were performed to check the compressive strength of the concrete specimen as per regulations provided by IS: 516-1959 at the end of 7 days and 28 days from curing. Mix 1 is prepared by replacing FS in different proportions with fine aggregates, and a minimum of 3 cubes were cast for each proportion to check the test results for compressive strength. Mix 2 is prepared by taking the optimum percentage of FS, which is $25 \%$, and trial mixes were prepared by replacing GGBS with Cement in different proportions. The number of cubes cast for each trail is three, and the strength is checked for every trial specimen at the end of 7 days and 28 days. Test results shown in Table 4 indicate that $25 \%$ of FS and 30\% of GGBS is the optimum percentages for utilizing industrial waste into the concrete mix and shows higher values for compressive strength when compared to the test results of conventional concrete.

Table 4 Test Results for Compressive strength

\begin{tabular}{|c|c|c|c|}
\hline Sr. No. & Mix Proportions & 7 Days & 28 Days \\
\hline $\mathbf{1 .}$ & Conventional concrete & 19.6 & 33.86 \\
\hline 2. & Trial 1 with 15\% FS & 20.56 & 30.36 \\
\hline 2. & Trial 2 with 20\% FS & 21.35 & 33.65 \\
\hline 3. & Trial 3 with 25\% FS & 24.04 & 36.79 \\
\hline
\end{tabular}

PAGE 80| Journal of Corporate Governance, Insurance, and Risk Management | 2021, VOL.8, Series. 2 


\begin{tabular}{|c|c|c|c|}
\hline 4. & Trial 4 with 30\% FS & 18.59 & 32.61 \\
\hline 5. & Trial 5 with $(25 \%+30 \%)$ & 25.78 & 37.93 \\
\hline 6. & Trial 6 with $(25 \%+40 \%)$ & 21.03 & 34.73 \\
\hline 7. & Trial 7 with $(25 \%+50 \%)$ & 19.79 & 31.55 \\
\hline
\end{tabular}

Source: Author's Compilation

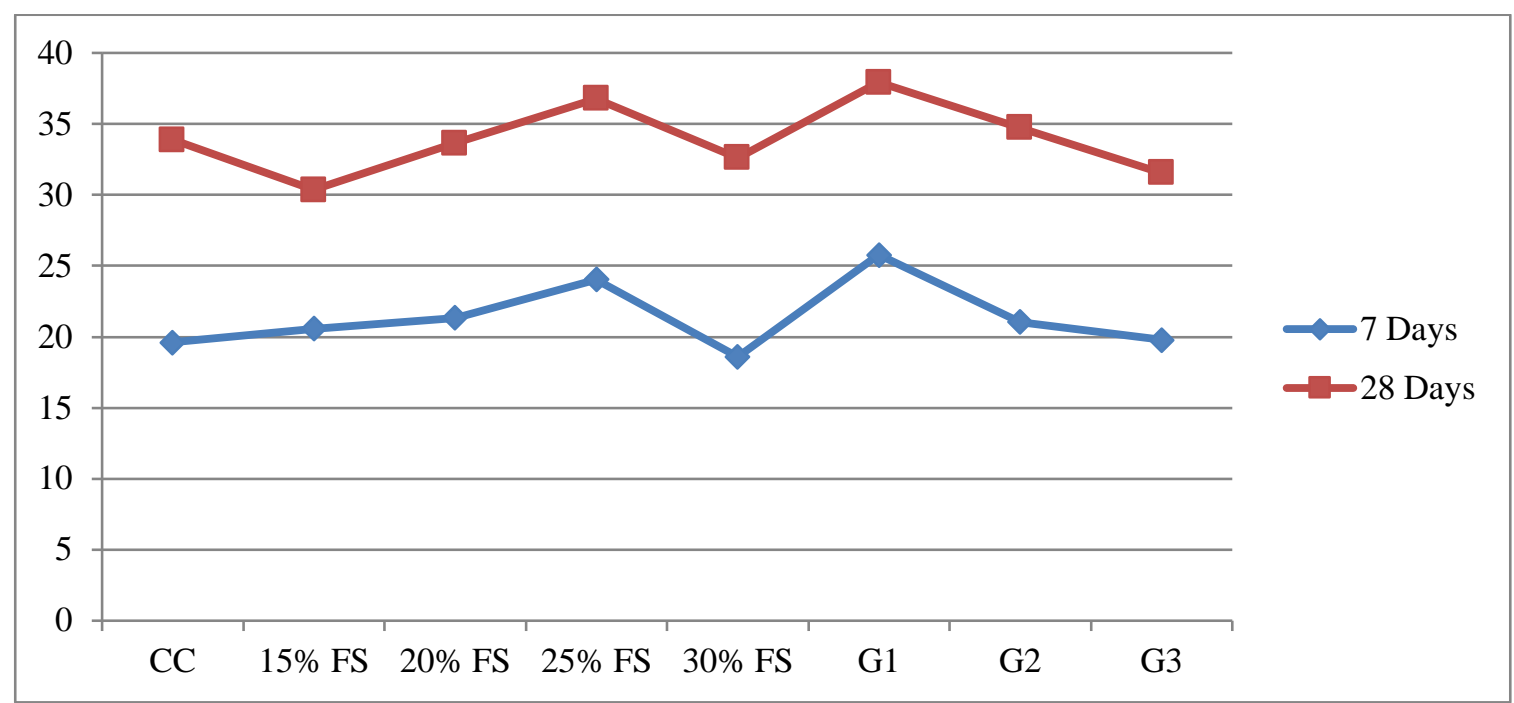

Figure 4 Test Results for Compressive strength

Source: Author's Compilation

\section{CONCLUSION}

1. The study conducted to assess the workability of the concrete indicated that the presence of foundry sand and ground granulated blast furnace slag helps increase the workability of the fresh concrete and shows a higher slump value when compared to the slump value of conventional concrete.

2. Our study indicates that a $25 \%$ replacement of foundry sand with fine aggregates shows a higher value for compressive strength and is the optimum percentage to partially replace the concrete mix.

3. The study concluded that the specimen prepared with $30 \%$ replacement of GGBS with cement and $25 \%$ replacement of FS with fine aggregates showed higher compressive strength at $25.78 \mathrm{kN} / \mathrm{mm}^{2}$ and $37.93 \mathrm{kN} / \mathrm{mm}^{2}$ for 7 and 28 days, respectively when compared with the test results for compressive strength of conventional concrete.

4. The study concludes that replacing $25 \%$ of FS and $30 \%$ of GGBS in concrete preparation can lead to eco-friendly green construction, and carbon emissions can be reduced by partially replacing the natural waste in the production of concrete. 
5. The study concludes that utilizing industrial waste for the production of concrete is beneficial for minimizing waste properly and contributing towards a healthier environment by producing greener concrete.

\section{REFERENCES}

Sheikibrahim, K., Sathish, S., Mohammed, F.A.S., Sathish, S. A., Karthika, H. and Shanmuganathan, N. 2018. "Ground Granulated Blast Furnace Slag (GGBS and GGBFS) and Flyash in concrete” (IRJET) e-ISSN: 2395-0056 p-ISSN: 2395-0072 Vol. 05 Issue:04.

Karri, S.K., Rao, G.R. and Raju, P.M. 2015. Strength and durability studies on GGBS concrete. SSRG International Journal of Civil Engineering (SSRG-IJCE), 2(10), pp.34-41.

Bhimani, D., Pitroda, J. And Bhavsar, J. 2013. A study on Foundry Sand: Opportunities for Sustainable and Economic Concrete. 2. 60-63. 10.15373/22778160/January2013/64.

Kumbhar, P.D. and Sangar, U.S. 2011. "Experimental study on mechanical properties of concrete blended with used foundry sand” Global Journal Engineering and Applied Sciences, ISSN 22492631, Pg. 122- 126, 2011.

IS: 10262-2009. 2009. “Guidelines for concrete mix proportioning” Bureau of Indian Standards, New Delhi. 